\title{
O RINOCERONTE DE DÜRER
}

Davi Augusto Santana de Lelis ${ }^{1}$

\section{DÜRER'S RHINOCEROS}

RESUMO: Realiza-se, neste artigo, uma breve reconstrução da história da filosofia, utilizando-se uma alegoria: a do rinoceronte de Dürer com objetivo de identificar como se estrutura a representação da realidade e o sistema jurídico brasileiro. Sem aprofundar, metodologicamente esta investigação filosófica perfaz quatro etapas do pensamento filosófico: o ser em si, o ser para mim, o ser da linguagem e a ética primeira. A análise de alguns exemplos atuais de categorização do direito, à luz dessas etapas do pensamento filosófico, aponta que ele (o direito) apenas pode a-presentar a realidade por fundamentar-se, ainda, em uma lógica epistemológica que busca a representação da realidade por meio da categorização dos institutos e de indivíduos em normas. Como solução há a ética da alteridade.

Palavras-chave: Filosofia do direito. Ética. Representação da realidade.
ABSTRACT: In this article, a brief reconstruction of the history of philosophy is made using an allegory: Dürer's rhinoceros. The main objective is to identifying how the representation of reality and the Brazilian legal system are structured. Without going further, methodologically, this philosophical inquiry makes four stages of philosophical thought: being itself, being for myself, the being of language and the first ethics. The analysis of some current examples of categorization in law, in the light of these stages of philosophical thought, points out that the law can only present reality because it is based on an epistemological logic that seeks the representation of reality by categorizing institutes and individuals into standards. As a solution there is the ethics of otherness.

Keywords: Philosophy of law. Ethics. Reality representation.

\footnotetext{
${ }^{1}$ Professor adjunto de Direito Administrativo do Departamento de Direito da Universidade Federal de Viçosa; Doutorando em direito pública na Pontifícia Universidade Católica de Minas Gerais.
} 


\section{INTRODUÇÃO: O RINOCERONTE DE DÜRER}

Em 1515, Manuel I, rei português, presenteou o Papa Leão X com um elefante e um rinoceronte. Os animais, capturados na índia, cruzaram o oceano Índico passando pelo Cabo da Boa Esperança e oceano Atlântico até desembarcarem em Lisboa. A chegada dos animais em Portugal causou sensação: àquela altura da história, poucos europeus haviam visto um rinoceronte. Acadêmicos e curiosos visitaram o animal e o descreveram em cartas que foram enviadas por toda a Europa.

Embarcados novamente no navio, os animais partiram rumo a Itália, em uma viagem que não se completaria. O navio naufragou na região noroeste da costa italiana, próximo à região de Gênova, o rinoceronte e o elefante, acorrentados ao convés, morreram afogados. Do rinoceronte restaram relatos e desenhos dos portugueses que chegaram às mãos do artista alemão Albrecht Dürer.

Albrecht Dürer foi um importante artista e seus trabalhos incluem pinturas, aquarelas e xilogravuras. Dürer, em contato com os relatos e esboços lusitanos que retratavam o rinoceronte, criou uma xilografia representando o animal. O rinoceronte de Dürer tem diversas incoerências anatômicas, entre elas placas e rebites feitos os de uma armadura, um corno extra nas costas e pernas com escamas. Apesar da imprecisão, a imagem feita por alguém que jamais havia visto um rinoceronte foi, por muito tempo, a referência para todos que buscavam representar o animal.

O rinoceronte, enquanto coisa, havia sido conceituado e classificado conforme a interpretação de Dürer. Essa realidade da xilografia ilustra o mundo do Direito que é exprimível pela linguagem e, na linguagem verbal, uma palavra só pode ser explicada por outra palavra. Um fato, coisa, relação, ou rinoceronte, da mesma forma, só se explicam por palavras. Afirma-se, pois, que a linguagem permite infinitas possibilidades de abertura para o mundo, dentre as quais o sistema jurídico, pensado em um viés ontológico, pretende diferenciar um instituto de outro por meio da classificação e conceituação.

Com a categorização estabelecem-se direitos e deveres. Havendo dúvida sobre a qual categoria pertence determinada coisa, haverá dúvida, igualmente, sobre quais direitos 
e deveres são devidos. O conhecimento depende desse reducionismo conceitual. Pimenta (2011, p.121) lembra que essa "é a ontologia como forma de se alcançar igualdade e universalidade, pressupostos do cálculo racional e dos sistemas políticos e jurídicos pensados como adequados na modernidade".

Ao se dizer que uma coisa é, autoriza-se sobre ela um poder. Levinas (1980) lembra que a história da ontologia é uma história do poder, que autoriza a coação e a violência. Conceituar, classificar, descrever, dizer o que é são maneiras de justificar a violência dentro do sistema jurídico. Apesar dessa visão que fundamenta uma teoria filosófica revolucionária, a ontologia faz parte do cotidiano, a conceituação ocorre pela divisão das coisas em elementos mais básicos com os quais se pode acessar e compreender a realidade.

O problema está em como essa realidade é compreendida e acessada. Poderia o Direito compreender a realidade por meio de seus conceitos, tal qual os contemporâneos de Dürer que, sem nunca terem visto um rinoceronte, acreditavam ser a xilogravura representação fiel da coisa rinoceronte? Ou acredita-se que a conceituação utilizada comumente pelo Direito, tanto no ensino quanto na prática, apenas a-presenta (uma)a realidade?

O objetivo deste texto é investigar se a estrutura do sistema do Direito ainda pautase na representação do mundo. Utilizando a alegoria do rinoceronte de Dürer, é possível encontrar quem decida ir com papel e pena até a savana para traçar o rinoceronte definitivo. $\mathrm{O}$ advento das máquinas fotográficas também traz, para alguns, a esperança de captar o rinoceronte em toda a sua essência. Descrições em pormenores, às vezes com o auxílio de outras ciências, também pretendem representar o rinoceronte. Mesmo com o auxílio de várias ciências e da tecnologia, o Rinoceronte pode ser representado?. E se o rinoceronte de Dürer fosse a natureza jurídica ou um instituto jurídico?

Metodologicamente, essas questões serão respondidas, seguindo os passos de Cruz (2011), que apreende a história do pensamento filosófico em quatro etapas: (i) a filosofia da antiguidade e do medievo, denominada Ser em si; (ii) o iluminismo que apresenta o Ser para mim; (iii) a virada linguística que trata do Ser da linguagem e; (iv) a escatologia que denomina as três primeiras etapas como ontologia e pretende construir uma ética 
primeira. A limitação deste artigo está em percorrer amplo período filosófico. Os pensamentos e caminhos apontados são, no entanto, suficientes para fundamentar as respostas às questões propostas, ao mesmo tempo em que instigam o aprofundamento futuro das vertentes de pensamento apresentadas.

Estruturalmente este artigo organiza-se da seguinte forma: na sessão seguinte analisa-se o fundamento da teoria ontológica que, tradicionalmente, trata a linguagem como forma de representação da realidade. Depois apresentam-se o fundamento da virada linguística e a possibilidade de uma teoria da ética primeira, em que a realidade apenas apresenta (uma)a realidade. Na última sessão apresentam-se as relações das ideias filosóficas com o sistema do direito, seguindo a conclusão.

\section{SER EM SI E SER PARA MIM: REPRESENTAÇÃO DO MUNDO}

Segundo Cruz (2011), a primeira etapa do pensamento filosófico, capitaneada pelos filósofos da antiguidade e do medievo, trata da relação sujeito/objeto denominada Ser em si. Sócrates, ao questionar o pensamento transmitido pela tradição, faz nascer a filosofia: a procura da verdade e a crítica do conhecimento. Iniciava o movimento que pretendia abandonar a doxa e edificar o conhecimento apenas com força na episteme. Nessa estrutura o conhecimento teórico se organiza em leis - não em sentido jurídico, mas científico - que permitem a elaboração de teorias justificáveis.

Platão, que se fundamentava em um idealismo forte, trata do conhecimento no Livro VII de $A$ República, texto conhecido como a alegoria da caverna. Nessa alegoria, as pessoas viveriam acorrentadas nas profundezas de uma escura caverna onde só teriam acesso ao mundo real, em imagens projetadas: conheciam apenas reflexos da realidade, de modo que desconheciam outro mundo e acreditavam ser a caverna o único e verdadeiro plano de existência. Dentre os cativos um liberta-se dos grilhões e sai da caverna em busca do mundo exterior, contemplando a verdade. Maravilhado com a descoberta, esse indivíduo retorna à caverna para dizer que as imagens na caverna são apenas projeções da realidade. Os acorrentados não acreditam nos relatos e acabam por matar o liberto. Para o pensamento platônico, o indivíduo que contempla a realidade seria o filósofo, que se liberta dos grilhões por meio do conhecimento e chega o mundo real (PLATÃO, 1989, p. 52). 
Interpretando a alegoria: Platão imaginava a existência do mundo das ideias perfeição -, e do mundo real, mera aparência do mundo das ideias. O mundo das ideias seria imutável, enquanto o real, mutável. Essa dedução leva à concepção de que a linguagem era mero instrumento para a comunicação, tornando o pensamento independente da linguagem e isomorfo de uma correspondência entre a estrutura linguística e ontológica. Havendo correspondência entre o significado e o significante, haveria relação direta entre o objeto e o conceito desse objeto. Assim, se a xilogravura do rinoceronte coincidisse com o relato dos que viram o animal em Lisboa, haveria a verdade sobre o que seria um rinoceronte. A essa ideia platônica, opõe-se seu discípulo mais famoso, Aristóteles, com suas teorias realistas.

Aristóteles concebe a ideia e a realidade por meio de conceitos. O sujeito entra em contato com o objeto, concebe uma representação de acordo com seus conhecimentos e atribui o significado ao objeto. O pensamento aristotélico surge em torno da essência, que existiria como substância ${ }^{2}$ primeira na ideia e como substância segunda na realidade. Segundo Aristóteles, haveria seres mais fundamentais do que outros. Animal e rinoceronte seriam gerais, enquanto o rinoceronte dado de presente ao Papa seria o Ser - ou substância - específica. Havia, portanto, elementos imutáveis que permitiriam conceituar o objeto. Para saber o que um Ser é, necessário seria encontrar a essência desse Ser; como o rinoceronte de Dürer, elaborado a partir da descrição dos portugueses que continha os elementos universais para a criação da xilogravura. Segundo as ideias de Aristóteles, aqueles que viam a xilogravura do Rinoceronte imaginavam ali a essência do animal.

De acordo com essa teoria, o conceito representa a realidade. A linguagem é o símbolo da realidade; afinal, é impossível pensar sem a linguagem. Se entre ideia e realidade há linguagem, há também distanciamento entre símbolo - a xilografia de Dürer , e realidade, o rinoceronte. $\mathrm{O}$ símbolo seria mais do que a realidade porque traria consigo a intervenção humana; mas seria menos do que a realidade, pois teria convenções que simplificariam ou adulterariam a realidade. No esforço de entender o que seria essa

\footnotetext{
${ }^{2}$ O termo substância é utilizado por Aristóteles como forma de expressar aquilo que é. No grego antigo o termo seria próximo ao verbo Ser. A construção aristotélica da substância é diversa da visão platônica das formas. Para Platão haveria formas, ideias que determinariam o que alguma coisa é. Para Aristóteles, a substância era a primeira e a mais básica das categorias, a que poderia ser predicada por outras características.
} 
representação Aristóteles elabora suas categorias.

Morici $(2008$, p.15) afirma que o termo categoria advém da forma inovadora com que Aristóteles utilizou o termo no grego antigo. A ideia influenciou Kant (2001) na elaboração da Crítica da razão pura. Esta obra valeu-se do termo categoria referiindo-se aos conceitos mais fundamentais do entendimento humano que, ladeados das formas puras de sensibilidade, formariam as condições para o conhecimento. Embora, em Categorias, não haja propósitos ou temáticas que serão abordados, tampouco uma definição do termo, vale-se da concepção de Aristóteles (2000) de que uma categoria seria o conjunto de objetos com características comuns que podem ser referidas por um conceito genérico. Nos dizeres de Morici (2008, p. 33), as categorias "pretendiam responder a indagação acerca de o que é possível querer dizer sempre que afirmo de um sujeito que ele é alguma coisa". Com as categorias a verdade seria obtida por meio da essência na qual se determina a forma de apreensão da realidade.

Considerando a xilografia de Dürer, a relação entre a ideia e a realidade ocorreria por correspondência e coerência: ao se olhar a xilografia do rinoceronte seria preciso compará-la com um espécime, permitindo assim estabelecer a correspondência e coerência entre o símbolo - xilografia -, e o objeto -, rinoceronte. Essa estrutura de pensamento se desenvolve pelo silogismo, contendo a premissa maior, a menor e a conclusão. Dessa forma, "a verdade surge de uma inferência meramente formal da correlação entre os termos do silogismo" (CRUZ, 2011, p.23).

O pensamento platônico e aristotélico é renovado no medievo pelas palavras de Santo Agostinho e São Tomás de Aquino. O neoplatonismo de Agostinho fundamenta a fé cristã; enquanto Aquino, também sob os dogmas do cristianismo, retoma a visão aristotélica da realidade. Santo Agostinho, seguindo os preceitos idealistas, divide a justiça entre a humana e a divina. A humana seria representada pela lex temporalen, uma lei imperfeita, mas essencial para a garantia de ordem social, pois ela comanda o comportamento humano para com seus iguais. Já a justiça divina seria representada pela lex aeterna, a que tudo governa, de modo perfeito, imutável, infalível e absoluto (BITTAR; ALMEIDA, 2004).

São Tomás de Aquino, pensador da Escolástica, adota um realismo moderado em 
que a verdade é obtida por meio da adequação entre uma verdade lógica - humana -, e uma verdade ontológica - divina. Nem todo pensamento teria correspondência com a realidade que só seria explicada pela capacidade de abstração do intelecto. A correspondência tomista não é mera coincidência entre pensamento e objeto, trata-se de uma constituição ontológica de cada ente, pois se existem objetos que correspondem ao pensamento é porque Deus pensou, em um primeiro momento, os objetos. Assim, a verdade ontológica informa que todo ente, por ter sido pensado primeiro por Deus, é verdadeiro. A verdade lógica, intelecto humano, esforça-se por identificar no significado do objeto o significado primeiro fornecido pelo divino. Para Aquino, a verdade lógica depende da verdade ontológica.

Dentro da lógica de adequação com o divino, a justiça seria um hábito, uma reiteração de atos voluntários com o fim da virtude. A distinção entre o justo e o injusto emergiria da ética, do meio termo nos interesses. Seguindo os preceitos aristotélicos, a justiça tomista poderia ser geral (feita em conformidade com a lei ou particular), que se subdivide em comutativa, correção de valores contratuais; e distributiva, dar a cada um o que é seu. São Tomás de Aquino acrescenta ainda a justiça legal, que teria como finalidade alcançar o bem comum por meio do elemento Direito. Mas como explica o próprio filosofo em sua obra Súmula Teológica, o bem comum representa não somente o bem da sociedade, mas, sobretudo o bem dos particulares (AQUINO, 1980). Assim, tem-se o Direito transformado em meio para se alcançar o justo.

Na lógica de Aquino, o rinoceronte seria verdadeiro, posto que primeiro havia sido pensado pelo divino. Ao humano caberia adequar o animal real ao animal ideal. A xilogravura de Dürer também seria verdadeira, pois, enquanto objeto, não teria escapado do pensamento primeiro de Deus. Os traços do artista não corresponderiam, entretanto, ao do animal real. Seria o esforço de uma verdade lógica em busca de completude com a verdade ontológica.

O pensamento tomista, embora tenha conseguido conciliar a fé e a razão, é questionado, entre outros, por Guilherme de Ockham com argumentação que conduz ao pensamento da modernidade. A ideia de substância e essência é substituída: o transcendente e o antropocentrismo perdem espaço e as ciências naturais florescem; com 
elas o pensamento humano ganha novos rumos. Chega-se à segunda etapa do pensamento filosófico, o lluminismo - que tem, nesse trabalho, principais expoentes em Descartes (1996) e Kant (2001) - que apresentam o Ser para mim, em que há uma relação de sujeito/objeto para a experimentação e observação e uma relação objeto/sujeito em que há obtenção, por meio da razão pura, de novos conceitos.

Nessa nova onda de possibilidades, o indivíduo ganha importância, enquanto a religião enfrenta a reforma protestante e a ciência torna-se experimental, abandonando a carga grego-medieval das suposições. O sistema de produção começa a se organizar em um modelo capitalista e o Estado sofre limitações quanto à possibilidade de intervenção na esfera individual. O Direito não mais origina-se no divino, tampouco é obra de um soberano; mas começa a ser entendido como produto do esforço humano. É nesse cenário de amplas mudanças que Descartes pretendia lançar O Mundo ou Tratado da Luz, em que discorreria sobre o heliocentrismo, mas a prisão de Galileu pelo Santo Ofício, por também expor o heliocentrismo, leva Descartes a escrever Discurso do Método onde justifica o seu ponto de vista (CRUZ, 2011, p.41).

Descartes (1996) encontrou salvação para a própria pele na estrutura de um conhecimento originário anterior, em semelhança à verdade ontológica de Aquino. Para o filósofo francês, os sentidos humanos não são capazes de compreender nada além das aparências, a verdade está na forma como o homem se coloca diante da própria verdade, na possibilidade de duvidar.

Na terceira de suas meditações, Descartes (2004, p.69) deseja provar a existência de Deus pelo princípio da causalidade. Apenas o divino poderia explicar a existência de um ser finito capaz de pensar a ideia do infinito. Em seu esforço teórico surgem mais dúvidas do que verdades, o que o leva a questionar se há algo de verdadeiro no mundo: a dúvida é o critério da certeza. Todo o conhecimento deveria passar pelo crivo da dúvida. Nessa ótica, o conhecimento torna-se solipsista. Segundo Pimenta $(2011$, p.50), a ideia do infinito que o ser humano - finito -, tem é dada por Deus - o próprio infinito. O ideatum ${ }^{3}$ da ideia do infinito não pode ser concebido dentro de um ser finito, mas é a ideia do infinito que

\footnotetext{
${ }^{3} \mathrm{O}$ ideatum significa o objeto do conhecimento, a realidade na qual as ideias devem encontrar correspondência.
} 
possibilita a correspondência entre conteúdo e ideia, objeto e forma, ideatum e ideia, noese e noema. Ao tentar pensar o infinito, o ser humano só conseguiria pensar uma parte, o finito.

De acordo com Descartes, os portugueses que estiveram frente a frente com o rinoceronte valeram-se de seus sentidos para apreender a imagem daquele animal. Mas os sentidos seriam falhos, incapazes de uma correta apreensão do objeto da observação. 0 conjunto dos sentidos não seria suficiente para apreender a essência do ser, os sentidos humanos não iriam além das aparências. O que dizer então de quem baseou-se em relatos para realizar uma obra, a xilogravura? Dürer sequer utilizara seus próprios sentidos para apreender o rinoceronte. Ao olhar o rinoceronte de Dürer, o observador precisaria formular a dúvida quanto a sua correspondência. Para Descartes, o conhecimento se pautaria em uma certeza primeira, a capacidade de duvidar. Ainda que grandioso, o rinoceronte de Dürer seria apenas uma xilogravura, um traço imperfeito na comparação com o Rinoceronte.

Kant (2001) teoriza o conhecer pela capacidade de se conceituar a multiplicidade de eventos sensíveis. O conhecimento só é possível se for ordenado, categorizado, confinado em leis de caráter geral. Dessa forma o conhecimento depende da existência do mundo, que uma vez observado pelo intelecto, permite a criação de conceitos puros.

Assim como Aristóteles, Kant (2001) também estabeleceu suas categorias, a da quantidade, a da qualidade, a da relação e a da modalidade. As categorias seriam conceitos a priori não encontrados na experiência, mas em funções lógicas do pensamento. $\mathrm{O}$ pensamento seria a união de representações na forma de juízos e inferências. É de sua terceira categoria que Kant extrai o imperativo categórico (SALATIEL, 2006).

De acordo com o imperativo categórico, a moralidade e a liberdade implicam-se reciprocamente. Agir moralmente é agir com liberdade e a única maneira de agir com plena liberdade é agir com moralidade. Deve-se, portanto, agir de acordo com algum princípio ou máxima que designe uma regra subjetiva sobre o que se está fazendo e o porquê; as causas das ações não podem ser desejos ou impulsos. Existem, segundo Kant (2001), duas formas de princípios pelos quais se pode agir: (1) o princípio material informa imperativos hipotéticos (desejos), trata-se de um princípio de racionalidade: deve-se agir 
de determinada maneira se se pretende satisfazer algum desejo; (2) o princípio formal descreve como alguém age sem fazer referência ao desejo, é o imperativo categórico que comanda de forma incondicional como deve-se agir.

Se a ação é realizada apenas para satisfazer os desejos, deixa-se que a natureza escolha no lugar do indivíduo, o que, para Kant (2001), não poderia acontecer, pois está-se sempre livre no sentido de que há sempre possibilidade de controle racional do Ser. $\mathrm{Na}$ eventualidade de falha na capacidade de controle racional das ações, a única maneira de agir livremente, exercendo a plena autonomia, é agindo-se de acordo com o imperativo categórico. Deve-se, assim, agir de forma que o princípio (máxima) torne-se uma lei universal. A autonomia estaria na ação moral permissiva pelo princípio (máxima), pois esta ação seria também permitida pela moral tornado a ação moral.

O direito em Kant passa a ser pensado como um idealismo transcendental, uma possibilidade de verdade a priori - conhecimento existente independente dos sentidos e da experiência -, alcançável por meio da razão pura. Desse conhecimento seria possível estabelecer juízos sintéticos - dependentes dos sentidos e da experiência -, por meio da razão prática. A ideia é estabelecida como um dever-ser, um imperativo categórico capaz de coordenar as ações práticas. Na razão prática há ação de acordo com os fins propostos. Cruz (2011, p.59) explica que a razão pode inferir imperativos categóricos - leis gerais tanto para as ciências naturais quanto para as ciências humanas, uma vez que a razão prática seria elemento suficiente para conduzir a vontade humana.

Para garantir que a vontade humana seja direcionada para o justo o imperativo categórico imporia a sua força. Esse imperativo ordenaria a ação independente de um objetivo determinado, independente da experiência, pois estaria construído a priori. De acordo com o imperativo, a ação deve ser 'uma máxima' capaz de ser uma máxima universal, como o não mentir. Em Kant, "a verdade assume uma ideia capaz de regular a ação e a conduta do ser humano, permitindo que sua razão prática se torne juiz da correção de suas ações" (CRUZ, 2011, p.63). A racionalidade de Kant (2001) informa que primeiro se é racional, depois se é ético.

O conhecimento deve cooperar com a sensibilidade para construir o espaço-tempo no qual a representação estará relacionada. Caso a representação não encontre 
compreensão no mundo objetivo, ela não pode ser designada por um 'eu penso', ou por meio do conhecimento via representações. Assim, o rinoceronte de Dürer poderia conter as características gerais do Rinoceronte. A xilografia faria as vezes de uma lei geral que representaria o Rinoceronte, pois toda representação deve relacionar-se com um objeto no mundo e com as categorias tidas como fontes fundamentais das leis da natureza (ROHLF, 2014). A experiência real, composta da apreensão, da associação, da reprodução e da recognição dos fenômenos, contem conceitos, que tornam possível a unidade formal da experiência e, com esta toda a validade objetiva (verdade) do conhecimento empírico (KANT, 2001, A125).

Wittgenstein (1968), na obra Tratado lógico filosófico, trata desses dois períodos filosóficos, ser em si e ser para mim, como representação ou espelhamento da realidade pela linguagem. O Tratado fundamenta-se em uma análise semântica da linguagem, em que a realidade pode ser representada pela linguagem; afinal a comunicação teria em seus signos sentidos únicos, capazes de gerar a perfeita compreensão. Aí, o primeiro ${ }^{4}$ Wittgenstein procura estabelecer as condições lógicas que o pensamento e a linguagem devem atender para representar o mundo.

Para demonstrar que uma proposição representa uma coisa real ou possível o primeiro Wittgenstein estabelece que uma proposição é uma representação figurativa dos fatos, assim como uma maquete representa figurativamente um edifício ou, em nossa alegoria, como a xilogravura de Dürer representa o rinoceronte. Todas as proposições que não precisavam ser confrontadas com a realidade seriam verdadeiras e denominadas de proposições tautológicas. As proposições que precisavam ser confrontadas com a realidade seriam denominadas de factuais; as desprovidas de verdade ou de qualquer conteúdo descritivo seriam denominadas contradições. Questões transcendentes, como o infinito, Deus e a Ética, seriam proposições absurdas do ponto de vista lógico; sendo impossível tratar destas questões, a alternativa seria o silêncio (WITTGENSTEIN, 1968, p.129).

Se o primeiro Wittgenstein estivesse com a razão, as palavras dos portugueses que

\footnotetext{
${ }^{4}$ É comum, nos estudos de filosofia, dividir o pensamento de Wittgenstein em duas etapas. Quando se faz referência à obra Tratado lógico filosófico, Wittgenstein recebe a alcunha de primeiro Wittgenstein. Após modificar seu pensamento, no livro Investigações filosóficas, passa-se a se referir a Wittgenstein como o segundo Wittgenstein.
} 
puderam estar diante do rinoceronte seriam proposições factuais e suficientes para que Dürer representasse perfeitamente o animal. O córneo extra nas costas, as escamas e a armadura com rebites, presentes no traço do artista, indicam que as descrições, ainda que fossem unívocas, permitiriam diversas interpretações. As palavras, por não conterem um único sentido, - know that -, acabaram resultando em uma obra fantasiosa que, embora tenha valor artístico relevante, mostrava-se incapaz de representar o Rinoceronte. Wittgenstein, após diversas discussões com o Círculo de Viena ${ }^{5}$ e com Frank Plumpton Ramsey, percebe que por esse caminho não conseguiria avançar na filosofia da linguagem e ruma para os jogos da linguagem em sua obra Investigações filosóficas. A terceira etapa do pensamento filosófico surge, e junto a ela o Ser da linguagem.

\section{SER DA LINGUAGEM E ÉTICA PRIMEIRA: A-PRESENTAÇÃO DO MUNDO}

O Ser da linguagem passa a compreender a realidade como a-presentação, as Investigações filosóficas de Wittgenstein (1999) ensinam que os conceitos dependem de sua aplicação - know how - e não são dados a priori - know that.

Na perspectiva do Ser da linguagem, o mundo torna-se o ambiente para o sistema semiótico. A linguagem é vista como forma de interação com o mundo, não em um sistema fechado que impediria os jogos de linguagem e o uso de uma gramática profunda, mas sim como uma prática social constantemente aberta para as interações com o mundo. Segundo Cruz (2011, p.113), "os conceitos não podem mais ser entendidos como significados determinados ou significados indeterminados, pois essa referência baseava-se na lógica semântica do grau de intenção e da extensão conceitual".

O segundo Wittgenstein abandona a cruzada em busca da essência da linguagem e afirma que a linguagem não é unívoca, mas um conjunto de linguagens praticável por meio de jogos (WITTGENSTEIN, 1999, p.52). Existe uma ampla variedade de jogos, explica Wittgenstein, há jogos de tabuleiro, esportes, de cartas, role play games, entre outros. Mas não há essência do que seja jogo. Existem semelhanças e distinções entre os diversos jogos. O mesmo se dá com a linguagem. Não há essência do que seja a linguagem, e sim

\footnotetext{
${ }^{5}$ Círculo de Viena é o como ficou conhecido o grupo de filósofos que, entre 1926 e 1936, reuniam-se na Universidade de Viena para reconstrução do empirismo, por meio do positivismo lógico e refutação da metafísica. Entre os frequentadores das reuniões estão Karl Menger, Richard Von Mises e Rudolf Carnap.
} 
diversas linguagens que se valem de regras, convenções e finalidades próprias, que formam os jogos de linguagem. O segundo Wittgenstein (1999, p.35) afirma que "O termo 'jogo de linguagem' deve aqui salientar que o falar da linguagem é uma parte de uma atividade ou de uma forma de vida". Desse modo, a "significação de uma palavra é seu uso na linguagem" (WITTGENSTEIN, 1999, p.43).

O que interessa no jogo de linguagem é o que o falante e ouvinte produzem com a linguagem. Aos partícipes do jogo cabe o dever de correção no acolhimento dos termos na prática social. A linguagem, na construção do Wittgenstein das Investigações filosóficas, deixa de ser veículo para de informações e converte-se em uma atividade social. De volta ao rinoceronte, a linguagem utilizada pelos portugueses na descrição seria fruto de um jogo de linguagem com o qual, provavelmente, Dürer não estava habituado? Teriam os lusitanos utilizado um símbolo que ia além da realidade? Ou se valeram de convenções que simplificaram e adulteraram o rinoceronte? Na outra ponta do jogo, Dürer teria fantasiado, em sua obra, indo além, ou ficado aquém das descrições? Na xilogravura há um jogo de linguagem que resultou em uma das mais famosas xilografias da humanidade; mas ela (a xilografia) não representa o Rinoceronte. O rinoceronte de Dürer a-presenta um rinoceronte.

As proposições do segundo Wittgenstein fazem com que a filosofia dedique-se às questões da linguagem e representação. Heidegger (2005a e 2005b), propõe-se a busca o Ser que, segundo suas reflexões, estaria perdido desde os pensamentos de Platão e Aristóteles. Todo o esforço filosófico em busca do Ser acabava sempre por estudar e explicar o Ente. Em busca de alternativa a essa estrutura filosófica, Heidegger, discípulo de Husserl na fenomenologia, escreve Ser e Tempo, umas das obras mais importantes da história da filosofia.

A filosofia de fundamento grego-medieval, iniciando-se com a tradição platônica, buscava entender o que era a verdade, ou como seria possível dizer que algo é alguma coisa por meio da ideia. Aristóteles, por meio de suas categorias, buscava entender as características das coisas para tornar possível dizer que algo é alguma coisa. Os esforços dessas duas tradições, que separavam o sujeito do objeto, tornavam o conceito de Ser o mais universal e o mais obscuro (HEIDEGGER, 2005a, p.28-29). Para Heidegger, o sistema 
categorial poderia ser o mais rico e estruturado, que ainda manteria toda ontologia cega e distorcida de propósito, se não compreendesse o sentido do Ser como tarefa fundamental.

Questionar o Ser seria um modo de ser do próprio Ente que questiona. Elaborar a questão do Ser significaria tornar transparente um Ente que questiona em seu Ser: "Como modo de ser de um ente, o questionamento dessa questão se acha essencialmente determinado pelo que nela se questiona - pelo ser" (HEIDEGGER, 2005a, p.33). Para esse Ser que existe em todos e tem a capacidade de questionar, Heidegger dá o nome de presença (Dasein). Para Heidegger não haveria separação sujeito-objeto, o Ser não estaria separado do mundo, é um ser-no-mundo. A pre-sença é abertura para como o mundo e realiza a compreensão de maneira que, ao mesmo tempo em que toca o mundo, também é tocada pelo mundo; não há separação sujeito-objeto. A pre-sença existe faticamente, não é transcedental, não é razão pura, não é um observador externo e neutro. Um indivíduo não é e nunca é dado sem mundo, nem há um eu isolado sem os outros.

O método fenomenológico utilizado pelo filósofo alemão tenta se depreender até mesmo dos vícios de linguagem que separam o sujeito do objeto, por isso sua obra possui gramática própria e termos com significação distinta do usual. A pre-sença é o Ser que não separa o sujeito do objeto, tão pouco é dado em um determinado momento. Nesse sentido o questionamento socrático de conhecer a si mesmo seria constante, pois a existência não seria mera presença, mas sim um caminho de possibilidades (CRUZ, 2011, p.137-138).

A pre-sença, portanto, constitui-se fundamentalmente em ser-no-mundo, que depende de uma abertura para uma existência própria, um poder ser que ainda não é. Ainda que se possa dizer o que a pre-sença é, restaria algo pendente, algo pertenceria ao fim, à morte. Além do ser-no-mundo haveria o ser-para-a-morte, um testemunho de um poder-ser próprio, fornecido pela consciência. O Ser estaria na temporalidade, que o levaria a condução de sua existência e na relação com a verdade (HEIDEGGER, 2005b).

O processo de compreensão do mundo aconteceria em um ciclo: como se interpretam e entendem as experiências e como a interpretação e experiência influenciam na experimentação dos acontecimentos para, novamente, influenciar como se interpretam e entendem as experiências. O estar no mundo não aconteceria de forma incondicional, certos fatores não podem ser alterados pela escolha, são coisas dadas, como o corpo com 
o qual se nasce, o período histórico em que se vive - isso torna o ser-jogado-no-mundo. A forma como se vive pode, no entanto, ser alterada, e a vida pode ser imprópria, quando se age como se fosse um anônimo (Dasman), apenas seguindo as normas do sistema social. Ou pode-se ter vida própria se desenvolve-se a potencialidade do Ser.

A existência imprópria é uma vida sem reflexão sobre o que é dado como abertura da pre-sença. É esconder-se atrás do impessoal e ser apenas mais um na multidão, "repetir sem questionar implica quase sempre ser aceito por aquilo que todos desde sempre aceitam. A existência inautêntica [imprópria] é sempre alienante, mas também confortável" (CRUZ, 2011, p.137). O movimento da vida imprópria para a vida própria se dá pela angústia trazida pelo nada. A forma como o nada será preenchido é uma escolha da pre-sença, trata-se de um poder-ser que acontece na temporalidade. Essa compreensão desentranha-se como um querer-ter-consiciência, uma escolha que importa em uma decisão, como um projetar-se no tempo, como angustiar-se e abrigar o ser-para-a-morte (HEIDEGGER, 2005b, p.97).

A temporalidade da pre-sença é limitada pela morte, mas na vida imprópria, no trato cotidiano, a pre-sença esquece da limitação temporal imposta à sua existência. Apenas ao compreender que, como pre-sença, se é também um ser-para-a-morte, é que a vida própria se revela, o supérfluo é abandonado e a percepção de que não se é melhor ou pior do que o Outro ocorre. Segundo Heidegger (2005a, p.45), "tempo é o ponto de partida do qual a pre-sença sempre compreende e interpreta implicitamente o Ser".

A verdade, para o pensamento heideggariano, seria um desvelamento que sempre geraria outro velamento. A apreensão do mundo dependeria sempre da perspectiva dada pelo observador. A perspectiva seria moldada por diversos fatores: política, cultura, economia, linguagem, história entre outros. A cada verdade desvelada, outras verdades possíveis seriam veladas. O relato dos portugueses desvelou uma verdade sobre o rinoceronte; como seres-jogados-no-mundo, eles valeram-se do horizonte de possibilidades do qual dispunham para descrever o animal. Dürer, da mesma maneira, desvelou o animal que seu momento temporal permitia. As histórias de cavaleiros e dragões devem ter exercido influência no traço do artista que, embora tenha desvelado uma verdade sobre o rinoceronte e feito de sua xilogravura referência para a a-presentação 
do animal, deixou velar (como era natural) outras verdades a respeito do rinoceronte.

A vida autêntica não significa necessariamente comportamento ético ou esclarecimento filosófico. Heidegger (2005a; 2005b), indiscutivelmente, possuía esclarecimento filosófico e exercia a potencialidade de seu Ser ao desenvolver as ideias de Ser e Tempo, mas faltava a ele humanismo. Quando o nazismo ascende ao poder na Alemanha, Heidegger filia-se ao partido e passa a colaborar com o regime totalitário, o que permite a interpretação de que, a partir de então, sua vida passa a ser imprópria, apenas de acordo com a vontade de um anônimo (Dasman). Das críticas ao pensamento heideggeriano surgem as ideias que motivam a ética primeira de Levinas (1980), quarta e última etapa dessa breve reconstrução filosófica.

A ética primeira de Levinas, movimento posterior à fenomenologia, denomina as três etapas posteriores como ontologia e trata a linguagem como evasão de si para o Outro. A filosofia ocidental, até aqui apresentada em três etapas - o ser para si, o ser para mim e o ser da linguagem - afirmava que era função da humanidade explicar os acontecimentos da realidade. Se a razão não for capaz de realizar uma explicação o acontecimento permanecerá obscuro. Quando se conhece algo, estabelece-se os universais; quanto mais universais sobre um determinado acontecimento ou objeto, mais se pode saber sobre ele; quanto mais padrões universais se conhece, mais se conhece sobre o mundo.

$\mathrm{Na}$ ontologia as coisas passam por um sujeito que é dado como um conceito neutro. Essa noção de Ser é o caminho para que tudo faça sentido, para que tudo tenha seu lugar, para que exista uma totalização - uma explicação racional para cada acontecimento. Se cientificamente tudo está em ordem e sujeito às leis, a sociedade também deve estar em ordem e sujeita às leis. A política, a sociedade e o direito, ao longo da história, caminharam no sentido de totalizar os indivíduos em padrões e normas cada vez mais universais (PIMENTA, 2011, p.26).

Segundo Levinas (1980, p.75), até mesmo Heidegger, que pretendia estabelecer uma pre-sença que se abre para o mundo, termina por subordinar a relação com Outrem à ontologia. O conhecer não poderia ser em si, não deveria se encerrar no "conchece-te $a$ ti mesmo" de Platão e tampouco transformar-se em constante busca nos escritos de 
Heidegger. Se para Heidegger a pre-sença está aberta para conhecer a si mesma, todo o tempo, ela encerra o conhecer em si mesma, independente do Outrem. Mesmo erro, segundo Levinas, cometido por Descartes, que na procura da verdade, tarefa eminentemente individual, reduzia-se à liberdade individual.

O 'eu penso' cartesiano, para Levinas, representa apenas a certeza de si e a desconsideração dos outros. O 'eu penso' cartesiano duvida de sua própria existência e encontra no infinito (Deus) a solução para os problemas. Entretanto, "a ideia do infinito não pode ser objetivada em um ente, pois transborda a noção de algo que pode ser descrito, explicado, compreendido" (SILVA, 2014, p.87).

Contra a ordem totalizante - que prende a humanidade nessa forma de pensar -, Levinas pensa o humano como uma singularidade que não se reduz a um conceito. A razão poderia até se esforçar a dizer o que uma coisa é, mas sempre restará algo (il y a). Cada evento ou coisa seria único em sua essência de modo que, após se afirmar todos os universais conhecidos sobre o evento ou coisa, ainda restaria algo. Algo que ultrapassa o sistema de referência do Ser que presencia o evento ou coisa, algo que é um anonimato, que não possuí nomes ou conceitos. Na matriz da ontologia o Outro é desconsiderado, reduzido a um conceito; ação que se desdobra em desrespeito e violência.

Mas como abandonar a condição da ontologia como filosofia primeira? Para Levinas (1980), a solução estaria em uma ética primeira, um acolhimento do Outro. Só quem se coloca de frente com a morte poderia se relacionar com o Outro, entendido aqui como uma alteridade insuperável, o absolutamente Outro (Outrem) que escapa da redução conceitual dada pela razão. Diferentemente do infinito cartesiano - que é colocado na figura de Deus - Levinas pensa o infinito como ente que é anterior à própria ideia do infinito. Desse modo, estar diante do infinito é estar diante da própria subjetividade, da concepção que nenhum conceito abarca: a infinitude do humano. Isso é transcendência.

Acolher o outro como Outrem se dá pelo frente a frente, pelo rosto. O rosto ultrapassa a ideia do Outro em mim, trata-se da recusa de ser reduzido a um conceito, de ser totalizado. $\mathrm{O}$ rosto a-presenta-se sem poder ser representado. A liberdade não é mais relacionada à subjetividade, quem impõe a norma é o Outrem. Desse modo, Levinas também contraria o pensamento kantiano, para quem a subjetividade estaria ligada à 
liberdade do indivíduo, tanto no plano teórico, quanto no plano prático; afinal, sem liberdade, o conhecimento e a ética não se sustentariam. Ao contrário do pensamento kantiano, Levinas entende que a liberdade não está fundamentada em um indivíduo autônomo e com livre-arbítrio, que racionalmente toma consciência do mundo para tomar a sua decisão livre e correspondente à máxima. A liberdade, em Levinas, está sujeita ao Outro. Somente pelo Outro se age com liberdade.

O rosto, quando se apresenta, anuncia o 'não matarás', que é, concretamente, um convite a uma relação sem paralelos, quer seja fruição, quer seja conhecimento (LEVINAS, 1980, p.176). O não matarás levinasiano é mais amplo que o não mentirás de Kant. O mandamento kantiano está inserido em uma perspectiva totalizante que projeta o Outro no Eu. O mandamento levinasiano é o acolhimento do Outro, autoriza a mentira se a ordem vem do Outrem. O não matarás expresso pelo rosto é uma alegoria que compreende toda a ética. A relação com o Outrem introduz no Eu o que não estava lá, impedindo a violência - 'não matarás' - e instaurando a razão - a ética. O que impede a corrupção do mandamento levinasiano é a existência de um terceiro na relação, terceiro que representa a vida em sociedade.

Se existisse apenas o Eu e o Outro, o Eu teria apenas obrigações, mas na sociedade existem diversas pessoas, surge então a figura do Terceiro. O estatuto do terceiro tem especial importância na concepção levinasiana de justiça. Em Totalidade e Infinito a justiça é fundamentada na relação de responsabilidade para com o Outro. Em Outramente que Ser, informa Pimenta (2011, p.92), a justiça é fundamentada como reconhecimento do terceiro, o que demanda uma relação de equidade, visto que viver em sociedade demanda uma relação assimétrica entre os indivíduos. Desse modo, entre o Terceiro e o Eu existe a mesma relação que o Eu estabelece com o Outrem. O Eu se relaciona com o Terceiro e com o Outro, comparando um com o outro e consigo mesmo, com vistas a encontrar outro que seja também responsável e para quem seu agir justo será direcionado.

Assim, a presença do rosto é também a presença do terceiro, de toda a humanidade que observa. A relação social é uma relação entre o Outro e o Mesmo, "sem qualquer intermediário de imagem ou de sinal, unicamente pela expressão do rosto" (LEVINAS, 1980, p.191). Pois "a presença do rosto - o infinito do Outro - é a indigência, presença do terceiro 
(isto é, de toda humanidade que nos observa) e ordem que ordena que mande" (LEVINAS, 1980, p.191). A sociedade, em Levinas, não é um conjunto de Eus, mas um infinito de Outros.

Segundo Levinas, as leis teriam condições de evitar certas consequências, mas a justiça só teria vez e sentido se conservar o espírito do des-inter-esse que fundamenta a ideia da responsabilidade pelo Outro. Esse seria o caminho para desfazer a ontologia (LEVINAS, 1982, p.91), afinal "a responsabilidade é o que exclusivamente me incumbe e que, humanamente, não posso recusar" (LEVINAS, 1982, p.93).

Se é o Outrem quem determina a liberdade, a responsabilidade é do Eu, quer o Outro aceite ou não. Na ótica levinasiana, o Outrem é o mestre do Eu, e dessa relação nascem no rosto a responsabilidade e a justiça. A relação ética está entre a passividade e a atividade contemporaneamente. Aceitar a relação com o Outro é o aspecto passivo; e agir em relação ao Outro é o aspecto ativo de uma responsabilidade intransferível. O Eu tornase responsável pelo Outro que, em uma estrutura social, é toda a humanidade. O Eu é responsável tanto pelo mocinho quanto pelo bandido, afinal o conceito 'bandido' não é capaz de dizer tudo sobre aquela determinada pessoa, além da redução conceitual ainda haveria algo. Nessa relação ética não há expectativa de recompensa para o Eu, não há segurança ou felicidade ao fim do comportamento ético, apenas sacrifício. A recompensa é para o Outro, afinal "preocupar-se com o outro acima de si mesmo é um absurdo possível" (PIMENTA, 2011, p.84).

Para Levinas, a "significação dos seres manifesta-se não na perspectiva da finalidade, mas na da linguagem" (1980, p.83). Somente por meio da linguagem, em que se ensina e é ensinado, seria possível renovar a promessa de esclarecer o que foi obscuro na palavra. Quem dá a significação é o Outrem e não o Mesmo ${ }^{6}$. Apenas por meio da palavra se aparece para o mundo, deixa-se de ser invisível. O mundo torna-se objeto na presença do Outro, com quem é possível falar; afinal, a linguagem não é uma atividade

\footnotetext{
${ }^{6} \mathrm{O}$ termo Mesmo é utilizado por Levinas para designar o caráter inalterado do Eu. Quem permanece o Mesmo realiza representação da realidade, não se altera nas relações com o Outro. Trata-se de um pensamento universal, um pensamento em primeira pessoa. "O pensamento universal é um pensamento na primeira pessoa. É por isso que a constituição, que para o idealismo, refaz o universo a partir do sujeito, não é a liberdade de um eu que sobrevive à constituição que permanece livre e como que acima das leis que ele terá constituído. $\mathrm{O}$ eu que constitui dissolve-se na obra que ele compreende e entra no eterno. A criação idealista é a representação" (LEVINAS, 1980, p.111).
} 
solitária. A verdade não teria, dessa forma, signo, significado e significante construídos de maneira egológica. Haveria, para a construção de uma verdade, necessidade do diálogo com consciência moral. A verdade estaria no acolhimento do Outro (LEVINAS, 1980, p.87).

Acostumou-se a pensar que, por meio de nossos sentidos, pode-se ver o rinoceronte e descrevê-lo, dando-Ihe significado e atributos, de modo que o conhecimento resultante seja verdadeiro, se o conceito universal de rinoceronte coincidir com a xilogravura. " $A$ verdade tão almejada pelo conhecimento seria uma coincidência média, como diria o ensinamento socrático (o homem como medida de todas as coisas)" (SILVA, 2014, p.94). Trata-se de movimento da mesmidade, de neutralidade, que totaliza um Outro ao Mesmo.

A teoria levinasiana promove uma nova concepção de mundo, uma concepção em que o infinito sempre excede o que se pensa. Essa concepção de mundo e de infinito não é diferente com relação ao Outro separado totalmente do Eu. Há, na teoria levinasiana, a demonstração da insuficiência da ontologia, há nela um pensamento infinito que a entificação não pode traduzir; para ilustrar, basta tentar conceituar o rinoceronte. A cada etapa do pensamento filosófico, ser em si, ser para mim e ser da linguagem, renovava-se o pensamento egológico, como o Eu pensava o rinoceronte sem, entretanto, ser possível representar o animal.

Ao final da exposição, as motivações, as relações entre os relatos e a xilogravura e entre essa e o rinoceronte são de menor importância se a ética primeira não for praticada. A xilogravura, ao final; é imprestável para representar o rinoceronte. Trata-se de uma tentativa fadada ao fracasso; afinal, após todo o esforço descritivo, ainda restaria algo, o rinoceronte não pôde ser totalizado e, fora da xilogravura, permanece infinito. Em um mundo totalizante, preocupado em categorizar tudo e todos, imaginar o acolhimento do Outro é uma alternativa transformadora.

A questão fundamental deste artigo é se o Direito compreende a realidade em seus conceitos. Pelo exposto até aqui, tem-se que o caráter ético do direito tem ficado em segundo plano. Estaria o trato jurídico a criar uma xilogravura após a outra, numa pretensão impossível de representar, por meio de normas, a realidade? 


\section{A XILOGRAVURA DO DIREITO}

Dialogando com a alegoria do rinoceronte de Dürer, verificou-se como a concepção de verdade se modificava no decorrer da evolução do pensamento filosófico. O Direito não se constituiu ao largo dessas concepções; muitos filósofos, ao tratarem de questões metafísicas, buscaram, em algum momento de suas carreiras, compreender as normas de regulação social e a estrutura do Estado. A tradição normativa também se fundamenta em uma ótica epistemológica de sujeito-objeto.

Cruz e Duarte (2013) afirmam que a estrutura positivista do Direito pauta-se numa necessidade de demonstração e na certeza de que a linguagem atua como representação da realidade. Nessa ótica, o Ser é diverso do Dever-Ser e os juízos empíricos distintos dos juízos normativos. Para a aplicação da norma, basta a utilização da subsunção e da ponderação, em geral, por um observador externo e inalcançável pela as inflexões mundanas. Nesse cenário a verdade é mera correspondência, coerência e certeza. A ética só encontra espaço em um segundo momento, pois primeiro a filosofia do Eu é aplicada por meio de uma racionalização metódica, pautada na episteme. Não há espaços para a doxa, a arte, a religião; assim, a legitimidade da lei torna-se, teoricamente, distinta da violência.

Os institutos jurídicos, comumente, são classificados numa pretensa natureza jurídica. Ao classificar e conceituar um determinado instituto, em uma dada natureza jurídica, imagina-se que a natureza jurídica é um gênero supremo e irredutível. Alguns intérpretes das Categorias de Aristóteles pensam dessa maneira, mas Morici (2008) demonstra que esse entendimento é equivocado.

Categorizar é responder ao 'o que é?'. A propósito da alegoria que ilustra esta reflexão, à indagação 'o que é esta coisa?', responder-se-á: 'um rinoceronte'. Resposta que leva à pergunta: 'o que é um rinoceronte?', cuja resposta é 'um animal', que leva à pergunta: 'o que é um animal?', cuja resposta aristotélica seria 'uma substância', que tem significado de enfim dizer o que é. A essa substância alguns interpretam como um gênero supremo e irredutível, esquecendo-se que uma substância pode ser colocada em duas categorias, em dois gêneros, o que destroi a ideia de categoria suprema ou, no caso do Direito, da natureza jurídica. 
Ao Direito: a pergunta 'o que é isso?', que tem como resposta 'uma concessão administrativa', leva a outra pergunta: 'o que é uma concessão administrativa?', cuja resposta é 'um contrato administrativo' que, por seu turno, leva à questão: 'o que é um contrato administrativo?', que obtem a simples resposta: é 'um contrato'. Contrato, aqui, seria a natureza jurídica, suprema, indivisível, a resposta definitiva sobre a questão. Esquecem-se os autores de que o contrato pode ser categorizado como uma manifestação bilateral de vontades, que pode ser de adesão ou ter os termos discutidos. Que um contrato pode não ser revisto unilateralmente, mas que a Administração Pública goza de alguns benefícios na realização de contratos, entre eles a rescisão unilateral. Todas essas questões também merecem sua explicação e demonstram que a natureza jurídica não é de forma, ou substância alguma, definitiva. A categorização em natureza jurídica pode ser um eterno questionar, por não se perceber que a redução conceitual é incapaz de compreender o infinito que a realidade apresenta.

Veja-se, por exemplo, o projeto de lei no. 6583 de 2013, que pretende criar o Estatuto da Família e conceituar família como a "união entre um homem e uma mulher, por meio do casamento ou união estável" (FERREIRA, 2015). Poderiam as palavras previstas no projeto contemplar todas as formas familiares que existiram, existem e vão existir? Ou estaria o legislador reduzindo o infinito da realidade do se deve conceber como família? Estaria a coisa 'família' sendo reduzida, por meio de uma egologia, ao seu horizonte finito de possibilidades? As famílias que existem fora e dentro do projeto sofrem violência com a conceituação. Uma redação conservadora vela uma realidade que continuará existindo à margem da lei. Uma redação conservadora não acolhe o outro, não age com ética primeira. Nesse caso a pretensão do legislador vai contra o mandamento levinasiano de que a linguagem deve ter estrutura ética e anunciar a inviolabilidade ética do Outrem. $\mathrm{O}$ rosto participa do discurso, mas a relação do Eu com o Outro não o inscreve no Mesmo. O rosto não pode ser reduzido a conceito, qualquer tentativa de se conceituar seria violar a ética e o infinito que se apresenta (LEVINAS, 1980, p.174). A família não deve ser totalizada em um conceito legal, deve existir na sociedade de modo infinito, sendo aceita e protegida legalmente em todas as suas formas.

O que dizer da maioridade penal? Convictos de que está aí a solução para a 
criminalidade, membros do Congresso Nacional, por meio da Proposta de Emenda à Constituição no. 223/2012 (BRASIL, 2015), julgam por bem reduzir de dezoito para dezesseis anos a idade limite para ser punido, não pelo Estatuto da Criança e do Adolescente, mas pelo Código Penal. Por que não quinze, quatorze, Treze anos? Poder-se-ia reduzir a maioridade penal à data do nascimento, essa opção legislativa seria a solução do problema ou apenas mais um rinoceronte de Dürer?

A ética levinasiana determina que a responsabilidade do Eu deve ser indistinta, tanto para o mocinho quanto para o bandido, afinal essas duas palavras, mocinho e bandido, são meras reduções conceituais incapazes de conter o infinito do indivíduo que apresentam. É cara a Levinas uma frase de Dostoievski: "Somos todos culpados de tudo e de todos perante todos, e eu mais do que os outros" (LEVINAS, 1982, p.90-91). Ao se considerar o conhecimento como algo mais amplo que a episteme, pode-se recorrer também a Guimarães Rosa, que não totaliza o mocinho e o bandido; afinal, "tudo é e não é... Quase todo mais grave criminoso feroz, sempre é muito bom marido, bom filho, bom pai, e é bom amigo-de-seus-amigos!" (ROSA, 2015, p.22). Nessa perspectiva, a responsabilidade e a justiça não são exclusivas do Estado, como o imaginam os teóricos contratualistas; a responsabilidade e a justiça pertencem a todos. Na ética levinasiana não se autoriza o pagamento do mal com outro mal, rememore-se que a ética de Levinas é uma relação desproporcional, que não resulta em felicidade ou recompensa. $\mathrm{Na}$ ética levinasiana, primeiro se é ético, depois racional.

Alguns defensores da redução acreditam que a prática criminosa por menores é simplesmente uma questão de escolha. Como se as pessoas que nascem em locais desprovidos de condições dignas de existência pudessem exercer os mesmos direitos e retribuir os mesmos deveres que pessoas nascidas em locais com condições dignas de existência. Na defesa de seus argumentos, países como a Noruega e Suécia - que fecham prisões por falta de detentos -, são postos em comparação com o Brasil, como se o horizonte de possibilidades de lá fosse idêntico ao daqui. Aos defensores da solução positivista, falta a percepção de que a solução dos problemas sociais não está na redação legislativa que se quer nova, mas sem a ética primeira.

A criminalidade não será combatida com outro mal, como o aumento do número de 
cárceres disponíveis, ou por meio da Parceria Público Privada que efetivamente privatiza o serviço de presídios, transformando as condenações penais em negócios de mercado. A solução está na igualdade social, na consecução dos objetivos constitucionais em se garantir a todos uma vida digna. A solução está na relação frente a frente com o rosto do Outro e no consequente acolhimento desse Outro dentro da ética primeira.

Poder-se-ia também relacionar o rinoceronte de Dürer aos conceitos já presentes na legislação, no ensino e na prática jurídica. O que dizer dos conceitos das pessoas administrativas, autarquias, empresas públicas, sociedades de economia mista e fundações públicas, contidos no artigo $5^{0^{7}}$ do Decreto lei no. 200 de 1967? Ferraz (2013), com fundamentação teórica na filosofia da linguagem, demonstrou que o texto legal não encontra representação na realidade. Trata-se de uma a-presentação incapaz de captar a essência das pessoas jurídicas. Como a-presentação, o conceito está sujeito às infinitas nuances da realidade.

Tome-se a empresa pública como exemplo: a lei diz que trata-se de uma pessoa jurídica; mas sob a ótica de que teoria? A teoria negativa, a realista, a da ficção jurídica? De direito privado, como se a distinção de Ulpiano, do século II, representasse a dinâmica jurídica atual? Que deve ser criada por lei, embora na Constituição, artigo 37, XIX registrase a expressão autorizada por lei? Será empresa pública se for criada ou se for autorizada? A empresa pública deve ter capital exclusivo da União, no termo União estaria também compreendida as pessoas da administração indireta federal? Dentre essas, uma sociedade de economia mista poderia ter capital em uma empresa pública? A empresa pública deve desenvolver atividades econômicas, o que pode ser tomado como ações estatais de cunho

\footnotetext{
${ }^{7}$ Art. 5o Para os fins desta lei, considera-se: I - Autarquia - o serviço autônomo, criado por lei, com personalidade jurídica, patrimônio e receita próprios, para executar atividades típicas da Administração Pública, que requeiram, para seu melhor funcionamento, gestão administrativa e financeira descentralizada. II - Emprêsa Pública - a entidade dotada de personalidade jurídica de direito privado, com patrimônio próprio e capital exclusivo da União, criado por lei para a exploração de atividade econômica que o Govêrno seja levado a exercer por fôrça de contingência ou de conveniência administrativa podendo revestir-se de qualquer das formas admitidas em direito. III - Sociedade de Economia Mista - a entidade dotada de personalidade jurídica de direito privado, criada por lei para a exploração de atividade econômica, sob a forma de sociedade anônima, cujas ações com direito a voto pertençam em sua maioria à União ou a entidade da Administração Indireta. IV - Fundação Pública - a entidade dotada de personalidade jurídica de direito privado, sem fins lucrativos, criada em virtude de autorização legislativa, para o desenvolvimento de atividades que não exijam execução por órgãos ou entidades de direito público, com autonomia administrativa, patrimônio próprio gerido pelos respectivos órgãos de direção, e funcionamento custeado por recursos da União e de outras fontes.
} 
empresarial? A Empresa Brasileira de Correios e Telégrafos presta serviço público ou a sua atividade teria natureza de atividade econômica? Por fim, a empresa pública pode ser constituída em qualquer forma societária admissível no direito, o que não denota nenhuma essência do que seja uma empresa pública (FERRAZ, 2013, p.168-181). Considerar o conceito de empresa pública escrito no decreto nํ. 200 de 1967 e acreditar que ali se diz o que é a Empresa Pública seria o mesmo que olhar a xilografia de Dürer e acreditar que ela é o Rinoceronte.

O que dizer do termo justo previsto para as indenizações de desapropriações? Nas desapropriações o interesse público é defendido ao se despojar alguém de seu bem. Em troca, a legislação exige a indenização prévia justa e em dinheiro, salvo nos imóveis rurais e urbanos que estejam em desacordo com a função social legalmente prevista, situação em que a indenização é devida por meio de títulos da dívida pública resgatáveis em parcelas anuais (MELLO, 2004, p.758- 759). Trata-se de uma violência autorizada do Estado para com o indivíduo (BENJAMIN, 2011). Tendendo a minimizar os danos, há previsão legal de que o valor a ser entregue ao desapropriado deve ser justo, mas como, diante dos jogos de linguagem, da pre-sença e do acolhimento do Outro seria possível determinar o que é justo?

Siqueira e Lelis (2014) pretenderam uma resposta possível para a determinação do justo. Cientes de que a legislação não encerraria todas as possibilidades de adequação entre a desapropriação e a indenização, preveem os juízes concederem danos morais como forma de aproximar a indenização do termo justo. Trata-se de uma aproximação, pois a justiça como aporia, como uma exigência im-possível de se calcular o incalculável (DERRIDA, 2010, p.29-30), não permitiria jamais que a decisão judicial representasse o justo; tratar-se-ia apenas de uma a-presentação. O dever de a-presentar o justo no caso concreto caberia ao julgador, servidor do Estado que não pode se furtar dessa impossibilidade, devendo, portanto, no exercício de sua função, ter em conta a alteridade, a ética primeira; afinal, “a justiça como experiência da alteridade absoluta é inapresentável, mas é a chance do acontecimento e a condição da história" (DERRIDA, 2010, p.55).

Em alternativa ao direito estruturado como epistemologia, Cruz e Duarte (2013) propõem que o conhecimento seja alcançado pela demonstração, mas igualmente pela atestação e pela deformação. Não para alcançar a certeza, mas para produzir a 
ambiguidade da pre-sença, da a-presentação e do infinito no Outro. O realismo, nessa perspectiva, é fraco, sem a realização de decisões pela mera subsunção/ponderação, mas por meio da associação. Afinal o indivíduo não é externo, faz parte do mundo, toca a realidade e é tocado por ela.. A verdade deveria ser construída por meio da responsabilidade, por meio da ética primeira. A fundamentação das decisões não ocorre por meio de uma justificativa racional, mas por meio de uma narrativa, em que a epistemologia contém e é contida pela doxa. Compreende a narrativa tanto a ciência, quanto a arte e a religião. $\mathrm{O}$ direito não seria uma estrutura normativa de acordo com a teoria das fontes, mas um modo de evasão e reconhecimento.

A estrutura do sistema do Direito, além do positivismo (CRUZ; DUARTE, 2013) na lida jurídica é ainda um esboço. O direito, ainda hoje, é como a xilogravura de Dürer não representa a realidade. Uma realidade que, segundo o trato jurídico, pode ser capturada por um observador externo e neutro e aplicada de acordo com a ideia de um homem médio. Trata-se de uma totalização que não concebe a realidade infinita.

\section{CONCLUSÃO: DIREITO IM-POSSÍVEL}

A história que conta a origem do rinoceronte de Dürer guarda semelhanças com os processos de criação, ensino e aplicação do direito. Tanto a xilogravura de Dürer, quanto o direito tentam representar a realidade. Entratanto, entende-se que a realidade pode apenas ser a-presentada. Na representação, que se busca em vão, a cada decisão, lei, portaria ou política pública deixa-se ao largo o aspecto ético, a evasão por meio da linguagem, o acolhimento do Outro em nome da aplicação da regra. Aos que enquadramse em determinada categoria, estabelece-se a gama de direitos e deveres aplicáveis, sem considerar o infinito que não se reduziu ao conceito geral.

O legislador, o estudante ou o aplicador do direito, quando inseridos em uma matriz ontológica de representação da realidade, entram em contato com relatos e esboços que retratam fatos e situações passíveis de classificação e solução por meio do direito. Até aqui, o processo jurídico muito se assemelha à arte do artista alemão, xilografia que não representa o rinoceronte; o direito criou o seu rinoceronte a sua xilografia. Assim como o rinoceronte de Dürer, a norma geral e abstrata tem diversas incoerências para com a realidade e os casos 
concretos a que pretende ser aplicada. Os exemplos tratados no texto, como o conceito de família, a redução da maioridade penal, o conceito de empresa pública, a definição do termo justo nas ações de desapropriação, são como as incoerências anatômicas do desenho de Dürer. Apesar da imprecisão da norma e da imagem, tem-se aí a referência.

O rinoceronte foi conceituado e classificado de acordo com a interpretação de Dürer; a norma, conceituada e classificada de acordo com a interpretação de juristas. Por meio da linguagem, busca-se a representação sem considerar que cada palavra está sujeita ao jogo de linguagem imaginado pelo segundo Wittgenstein. Ao se prever normas com supostos conceitos fechados, contraria-se a ideia de que a linguagem permite infinitas possibilidades de abertura para o mundo, e desconsidera essas aberturas essenciais para a constituição da pre-sença que, em constante movimento no tempo e no espaço, deveria interpretar e aplicar a norma.

A ciência do direito, por meio da categorização, estabelece direitos e deveres, em uma estrutura que reduz e aprisionam numa natureza jurídica os institutos, direito, deveres e pessoas. Se a realidade escapa à tábula jurídica, alguns ousam dizer que trata-se de um direito sui generis. Situações que não comportam a classificação, como os direitos sui generis, poderiam ser a oportunidade de se abandonar a matriz ontológica, e perceber que cada situação, cada indivíduo, guarda um infinito que não pode ser representado por uma norma específica ou genérica. Entretanto, por foça da tradição, a classificação persiste.

Demonstrou-se que dizer o que uma coisa é autoriza sobre ela um poder, uma coação, uma violência. A conceituação, a classificação, o dizer o que é são maneiras de justificar a violência na aplicação do direito. A realidade passa a ser acessada e compreendida como passível de redução à normas gerais, por meio da linguagem. E ao se olhar para as normas, pode-se acreditar estar olhando para a realidade, pois imagina-se haver ali um espelhamento. Agir assim assemelha-se a olhar o rinoceronte de Dürer e acreditar no espelhamento da realidade: "eis aqui o rinoceronte". Entretanto, demonstrouse que essa forma de conhecimento não é adequada, e que tanto a xilogravura de Dürer, quanto as normas jurídicas a-apresentam uma realidade, que deve ser interpretada de acordo com padrões éticos.

Essa busca de um direito justo é ainda uma im-possibilidade. A justiça que aqui se 
busca, quando categorizada a um modelo ontológico de representação, afasta-se do direito. O conhecimento, quando entendido apenas em uma matriz epistemológica, reduz o direito aos limites de sua ciência, carecedora de demonstração nos termos de uma razão praticada em noese-noema.

O resultado dessa prática é um constante rinoceronte de Dürer. A lei, ao definir um conceito, não faz mais que uma xilogravura do direito que, na realidade, permanece irredutível à classificação. A decisão judicial, tomada em uma perspectiva ontológica e de representação, que profere os direitos e deveres aplicáveis de acordo com a norma geral, está apenas relatando como é o rinoceronte conforme a xilogravura. Sem acolhimento do Outro, toma-se como única verdade uma obra - lei -, produzida a partir de relatos, interesses, horizontes de possibilidades, subjetividades e, assim, não se alcança a finalidade - justiça -, para qual o instrumento - direito -, existe.

O direito não deveria ter preocupação com o conceito do Eu, mas com o conceito do Outro para, assim, não tentar encontrar a assimetria nas características gerais, proporcionais, distributivas, equitativas. Mas, sim, a dissimetria naquilo que difere o Eu do Outro. Nessa nova perspectiva, a aplicação do direito não se preocuparia apenas com a aplicação da regra geral, mas trataria de recriar a regra geral a cada caso, de acordo com as peculiaridades que se apresentem. Eis a condição ética para a aplicação do direito alcançar a sua finalidade primeira: a justiça entre diferentes. Ou teria o direito finalidade(s) outra(s) que não a justiça?

\section{REFERÊNCIAS}

AQUINO, Santo Tomás de. Suma Teológica. Secunda Secudaem partis q. LXXXIX, art. I Tradução de Alexandre Correia. 2. ed. Porto alegre. Sulina. Grafosulk. 1980.

ARISTOTELES. The Categories. Traduzido por E. M. Edghill. Champaing: Project Gutenberg Etext, 2000.

BENJAMIN, Walter. Escritos sobre mito e linguagem (1915-1921). São Paulo: Editora 34, 2011.

BITTAR, Eduardo C. B; ALMEIDA, Guilherme Assis de. Curso de Filosofia do Direito. 3. ed. São Paulo: Ed. Atlas, 2004. 
BRASIL. Proposta de Emenda à Constiuição no. 223/2012 - Dispõe sobre a alteração do artigo 228 da Constituição Federal, propondo a redução da maioridade penal. Disponível em: http://www.camara.gov.br/proposicoesWeb/fichadetramitacao?idProposicao= 560839. Acesso em: 30 abr. 2015.

CRUZ, Álvaro Ricardo de Souza. A resposta correta: incursões jurídicas e filosóficas sobre as teorias da justiça. Belo Horizonte: Arraes editores, 2011.

CRUZ, Álvaro Ricardo de Souza; DUARTE, Bernardo Augusto Ferreira. Além do positivismo jurídico. Belo Horizonte: Arraes. 2013.

DERRIDA, Jacques. Força de lei. 2. ed. São Paulo: Martins Fontes. 2010.

DESCARTES, René. Discurso do Método. Tradução de Maria Ermantina Galvão G. Pereira. São Paulo: Martins Fontes, 1996.

DESCARTES, René. Meditações sobre Filosofia Primeira. Tradução de Fausto Castilho. Campinas: UNICAMP. 2004.

FERRAZ, Leonardo de Araújo. $\mathbf{O}$ administrativismo no século XXI: por uma visão renovada dos conceitos jurídicos indeterminados. Belo Horizonte: D'Plácido, 2013.

FERREIRA, Anderson. Minuta do projeto de lei no. $\mathbf{6 5 8 3}$ de $\mathbf{2 0 1 3}$ - dispõe sobre o estatuto da família e dá outras providências. Disponível em: http://www.camara.gov.br/proposicoesWeb/prop_mostrarintegra?codteor $=1159761 \&$ file name=PL+6583/2013. Acesso em: 29 abr. 2015.

HEIDEGGER, Martin. Ser e Tempo - Parte I. Tradução de Márcia Sá Cavalcante Schuback. 15. ed. Rio de Janeiro: Vozes, 2005a.

HEIDEGGER, Martin. Ser e Tempo - Parte II. Tradução de Márcia Sá Cavalcante Schuback. 13. ed. Petrópolis: Vozes, 2005b.

KANT, Immanuel. Crítica da razão pura. Tradução de Manuela Pinto Santos e Alexandre Fradique Morujão. 5. ed. Lisboa: Fundação Caloutre Gulbenkian, 2001.

LEVINAS, Emmanuel. Ética e Infinito: diálogos com Philippe Nemo. Tradução de João Gama. Lisboa: Edições 70, 1982.

LEVINAS, Emmanuel. Totalidade e Infinito. Lisboa: Edições 70, 1980.

MELLO, Celso Antonio Bandeira de. Curso de direito administrativo. São Paulo: Malheiros, 2004.

MORICl, Igor Mota. As categorias de Aristóteles e suas categorias. Dissertação de mestrado. Orientador Fernando Rey Puente. Faculdade de Filosofia e Ciências Humanas da UFMG. Belo Horizonte, 2008.

PIMENTA, Leonardo Goulart. Difícil Justiça: a relação entre justiça e direito a partir do pensamento de Emmanuel Levinas (tese de doutorado). Orientador: Márcio Antônio de Paiva. Pontifícia Universidade Católica de Minas Gerais. Belo Horizonte, 2011.

PLATÃO. A República. Livro VII. Brasília: UNB/Ática, 1989.

ROHLF, Michael. Immanuel Kant. The Stanford Encyclopedia of philosophy. Edmard N. Zalta (ed). 2014.

ROSA, João Guimarães. Grande Sertão: Veredas. 21. ed. Rio de Janeiro: Nova Fronteira, 2015. 
SALATIEL, José Renato. Peirce e Kant sobre categorias: Parte I - dedução metafísica e reviravolta semiótica. Cognito-Estudos: Revista Eletrônica de Filosofia, São Paulo, v. 3, n. 1, p.79-88, jan./jun. 2006.

SILVA, Guilherme Ferreira. Uma análise crítica da teoria das capacidades institucionais: o direito para além do formalismo com Emmanuel Lévinas. Dissertação de Mestrado. Orientador: Álvaro Ricardo de Souza Cruz. Pontifícia Universidade Católica de Minas Gerais, Programa de Pós-graduação em Direito, 2014.

SIQUEIRA, Daniel J. C.; LELIS, Davi Augusto Santana de. Indenização por valor afetivo e o valor do justo no procedimento desapropriatório. In: Filipe Reis Melo; Maria Lírida Calou de Araújo e Mendonça; Yuri Schenider. (Org.). Direito e Administração Pública II. 1. ed. Florianópolis: CONPEDI, 2014. p. 339-357

WITTGENSTEIN, Ludwig. Investigações filosóficas. Tradução de José Carlos Bruni. São Paulo: Nova Cultura, 1999.

WITTGENSTEIN, Ludwig. Tractatus logico-philosophico. Tradução de José Arthur Giannotti, São Paulo: Editora da Universidade de São Paulo, 1968. 